Zhong, L. (2017). Using Learning Analytics to Improve Instructional Support Design for Online Learning.

Journal of Educational Technology Development and Exchange, 10(2), 25-36.

\title{
Using Learning Analytics to Improve Instructional Support Design for Online Learning
}

\author{
Lin Zhong \\ Southern Illinois University Carbondale, USA
}

\begin{abstract}
Learning analytics has been demonstrated as a great tool to evaluate quality of instructional design. This study examined how instructors can utilize learning analytics to improve online learning support design. 128 students from a southern university in United States participated in this study. All learning data related to learners and online learning environment was collected and analyzed. Results showed that learning analytics results were very helpful for instructors to improve online instructional support timing, adjust learning module design, and enhance learning materials accessibility.
\end{abstract}

Keywords: instructional design, learning analytics, learning data, online learning

\section{Introduction}

Successful online learning requires high quality of online learning support, which should provide right learning support at the right time for online learners. However, such requirement is difficulty to achieve for faculty and instructional designers. The main reason for the difficulty is that current evaluation methods are not able to provide accurate information for faculty and instructional designers to decide when to provide what learning support. Most faculty and instructional designers rely on their personal teaching experiences to design learning support for online learners. The quality of learning support cannot be guaranteed because of the varied personal experience and background. There is a need to find other methods to enhance learning support quality.

The emerging trend of utilizing learning analytics in education has provided a possible way for faculty and instructional designers to improve learning support quality. Learning analytics enables online instructors to examine pedagogical and technological assumptions embedded in instructional design quantitatively (Grant, 2012; Jo, Kim, \& Yoon, 2014; Kim \& Park, 2016; Lockyer \& Dawson, 2011; Zhong, 2016). Based on learning analytics results, instructors are able to decide what learning support should provide and when to provide such support ( FidalgoBlanco, Sein-Echaluce, García-Peñalvo \& Conde, 2015; Hernández-García, González- 
González, Jiménez-Zarco \& Chaparro-Peláez, 2015; Lockyer, Heathcote, \& Dawson, 2013; Mattingly, Rice, \& Berge, 2012).

However, few studies, especially empirical studies, were found to examine how instructors can utilize learning data to improve learning support for online course. Wellestablished empirical studies are required to provide examples of using learning analytics to support teaching efficacy and learning efficiency (Ifenthaler, 2014). Aimed at filling this gap, this study explored how instructors can utilize learning analytics to improve quality of learning support design.

\section{Literature Review}

\subsection{Learning analytics}

Learning analytics has been defined as the "collection, analysis, and application of data accumulated to assess the behavior of educational communities" (Larusson \& White, 2014, p1). Methods for conducting learning analytics include statistical techniques, information visualization, data mining, and social network analysis (Chatti, Dyckhoff, Schroeder, \& Thus, 2012). In this study, learning analytics refers to using statistical techniques to analyze learning data of online learners and the learning environment in which learning occurs with the intent of exploring online learners' learning patterns and improving learning support design quality. Learning data used for statistical analysis includes time spent on learning, learning management system visiting number, learning device, and other qualitative data that is related to learners and the online learning environment (Chatti et al., 2012; Papamitsiou \& Economides, 2014).

\subsection{Learning support}

Learning support refers to the information and resources provided for learners with the purpose of engaging learners in the learning processes (McLoughlin, 2002). Instructional support, peer support and technical support are identified as three aspects of learning support (Lee, Srinivasan, Trail, Lewis, \& Lopez, 2011; McLoughlin, 2002). Instructional support refers to learning guidance, such as course navigation, reading materials, tutorials on assignments, instructions of learning modules, and other instructional purpose resources. Peer support refers to help from other students in the same class. This type of support usually comes from group projects, group discussion, peer evaluation and study groups. Through the interaction process with other students, online learners are able to form a sense of learning community that makes learning more efficient and effective (Lee et. al, 2011). Technical support aims to solve technical issues that online learners may encounter (Muilenburg \& Berge, 2005). Examples of technical support may include tutorials, basic web skills and learning management system navigation.

Effective learning support design is characterized by highly focused goal orientation, flexible adaptability, high accessibility, high alignment, high experiential value, supported collaboration, strong constructivism, learner-regulated learning orientation, multi-dimensional multiplicity and high granularity (McLoughlin, 2002). These requirements of effective learning support design are also referred as ten-dimension design guidelines of learning support (McLoughlin, 2002; Mullen \& Tallen-Runnels, 2006). Because of limited time and resources, this study only examines the accessibility feature of learning support design. According to McLoughlin (2002), online learning requires flexible accessibility of learning support, referred as just-in-time learning 
support. Current literature suggests tutorials and online frequently asked question tool as the ways of providing just-in-time learning support (Lonn, Aguilar \& Teasley, 2015). However, only using tutorials and online frequently asked question tool is difficult to determine exactly when learners need support or just-in-time support. Therefore, learning data related to learners and online learning environment is taken into consideration into improving learning support design (Greenhow, 2006).

\section{Research Questions}

The following research questions were investigated in this study:

1.How can instructors utilize learning analytics results to improve instructional support design for online courses?

2.How can instructors utilize learning analytics results to improve peer support design for online courses?

3.How can instructors utilize learning analytics results to improve technical support design for online courses?

\section{Method}

This study chose a mixed-method research design to examine the correlation between learning data and learning performance and to explore the learning patterns and teaching strategies through learning analytics. Mixedmethod design was appropriate for this study because both quantitative and qualitative data were collected and interpreted in this study with the purpose of obtaining full understanding of online learners' behaviors (Creswell \& Clark, 2011).

\subsection{Research setting}

An undergraduate online course of teacher education program at a southern university in United States was selected as research setting in this study. This course, delivered via learning management system (Blackboard), is a core course in teachers' education programs. Students are required to read book chapters, view video clips, listen to podcasting, and conduct nine hands-on projects. Additionally, students are required to keep an online learning journal (blog), which is a culmination of their work and completed as a blogfolio at the end of semester. All learning materials are organized into ten learning modules, including tutorials, PowerPoint, audio or video lecture, PDF documents, and other reading materials. Every week, students explore each learning module, conduct reading and handson projects in the module, and reflect on other students' blog posts. At the end of semester, students will post a course reflection that demonstrates their learning experience in this course.

Students are provided with instructor's contact information, which includes an email address, office phone number, and cell phone number. Students are able to email or call their instructor when they need help with the course and assignments. Blackboard also provides an email module that students can use to send email to their instructor and/ or classmates through Blackboard. Three online meetings are scheduled for students throughout the semester as additional ways of communication with the instructor. The online meeting lasts at least one hour. The instructor answers students' questions and demonstrates the hands-on projects through these scheduled meetings. The meeting will be video-recorded and stored in Blackboard and students are able to view the recorded meeting after the meeting time. 


\subsection{Participants}

Participants in this study are 128 students who enrolled in the undergraduate online course. All participants are part-time students and have full-time jobs. The average age of participants is 35 years old. Ninety percent of participants are female. Students were provided with a research participation consent form after all grades were posted at the end of the class. Recruiting participants after the grades post can reduce students' concerns that their participation may affect their final grades in this course. Participation is voluntary. Any students who are interested in this study can participate by emailing the consent forms.

\subsection{Data collection}

In this study, all learners' data across two years was collected from Blackboard, the information management system, teaching materials from instructor, and students' assignments. All the data related to students' learning activities were extracted from Blackboard. Students' demographic data was collected from the information management system, which consisted of students' gender, age, major, and educational stages. Information management system is a student management system where students can register courses, review grades, and financial information. Learning device data was collected through Google Analytics that embedded in Blackboard. Instructor's teaching materials included the syllabus, course schedule, learning modules, assignment instructions, video clips, audio lectures, and teaching websites. Students' assignments included students' blog posts, grades, comments on blog posts, and course reflections.

\subsection{Data analysis}

All the data extracted from Blackboard and the information management system were organized in Excel file. Instructor's teaching materials and students' assignments were also documented for analysis. Descriptive statistical analyses were conducted for data from Blackboard and information management system. Additionally, linear regression was conducted to describe data from Blackboard, the information management system and to explain the relationship between students' grades and other possible variables such as time spent on learning and learning module visiting numbers. Content analysis was chosen to analyze instructor's teaching materials and students' assignment materials because this study contains a large amount of materials that should be reduced to answer research questions (Saldana, 2013).

\section{Results}

Learners' data were categorized in three types, including time spent on learning, visiting numbers, and learning devices. The first type of learning data, time spent on learning, contains average learning hours of each grading level, average weekly learning hours, and learning time of day. The second type of learning data, visiting numbers, includes monthly visiting numbers of each student and overall visiting numbers of each learning module. The last type of learning data, learning devices, consists of learning devices information, mobile learning devices information, operating system, and browsers used to access the learning management system. All the data is summarized in Table 1 . 
Using Learning Analytics to Improve Instructional Support Design for Online Learning

Table 1. Summary of learning data

\begin{tabular}{|c|l|}
\hline Data Category & Learner Data \\
\hline \multirow{4}{*}{ Time Spent on Learning } & Average Learning Hours of Each Grading Level \\
\cline { 2 - 3 } & Average Weekly Learning Hours \\
\cline { 2 - 3 } & Learning Time of Day \\
\hline \multirow{2}{*}{ Visiting Number } & Monthly Visiting Numbers of Each Student \\
\cline { 2 - 2 } & Overall Visiting Number of Each Learning Module \\
\hline \multirow{2}{*}{ Learning Device } & Learning Device \\
\cline { 2 - 2 } & Mobile Learning Device \\
\cline { 2 - 2 } & Operating System \\
\cline { 2 - 2 } & Brower \\
\hline
\end{tabular}

\subsection{Time spent on learning}

Time student spent on learning is an important indicator of effective learning. Average course learning time for each grading level was collected and analyzed (Table 2). The average learning hours for grade A are 24.07 hours, which is almost four times of learning hours for grade B students. The average learning hours for grading $\mathrm{C}$ is 3.74 hours, which is more than 24 times of learning hours for grade D.

Average learning hours for each day of a week was also included in this study (Table 3). Students are most likely to study on Sunday rather than other days of a week. Tuesday and Thursday are the least likely learning days. Learning hours on Monday and Wednesday have dropped by $40 \%$ compared to Sunday. Learning time spent on Friday and Saturday are quite similar.

Table 2. Average learning hours for each grading level

\begin{tabular}{|l|l|}
\hline Grading Level & Average Learning Hours \\
\hline A & 24.07 \\
\hline B & 6.99 \\
\hline C & 3.74 \\
\hline D & 0.14 \\
\hline F & 0 \\
\hline
\end{tabular}


Table 3. Average weekly learning hours

\begin{tabular}{|l|l|}
\hline Day & Average Learning Hours \\
\hline Sunday & 105.45 \\
\hline Monday & 62.34 \\
\hline Tuesday & 44.33 \\
\hline Wednesday & 65.76 \\
\hline Thursday & 46.93 \\
\hline Friday & 55.15 \\
\hline Saturday & 57.40 \\
\hline
\end{tabular}

Besides preferred learning day, learning data also indicated that students had a preferred learning time of day (Figure 1). In this online course, $7 \mathrm{pm}$ was the most preferred learning time followed by $8 \mathrm{pm}$ and $9 \mathrm{pm}$. Lunch time between $12 \mathrm{pm}$ and $14 \mathrm{pm}$ was another preferred learning time.

\subsection{Visiting numbers}

Researching visiting number of learning materials is another revealing way to explore learning patterns in online learning environment. The course's average monthly visiting numbers were collected and analyzed

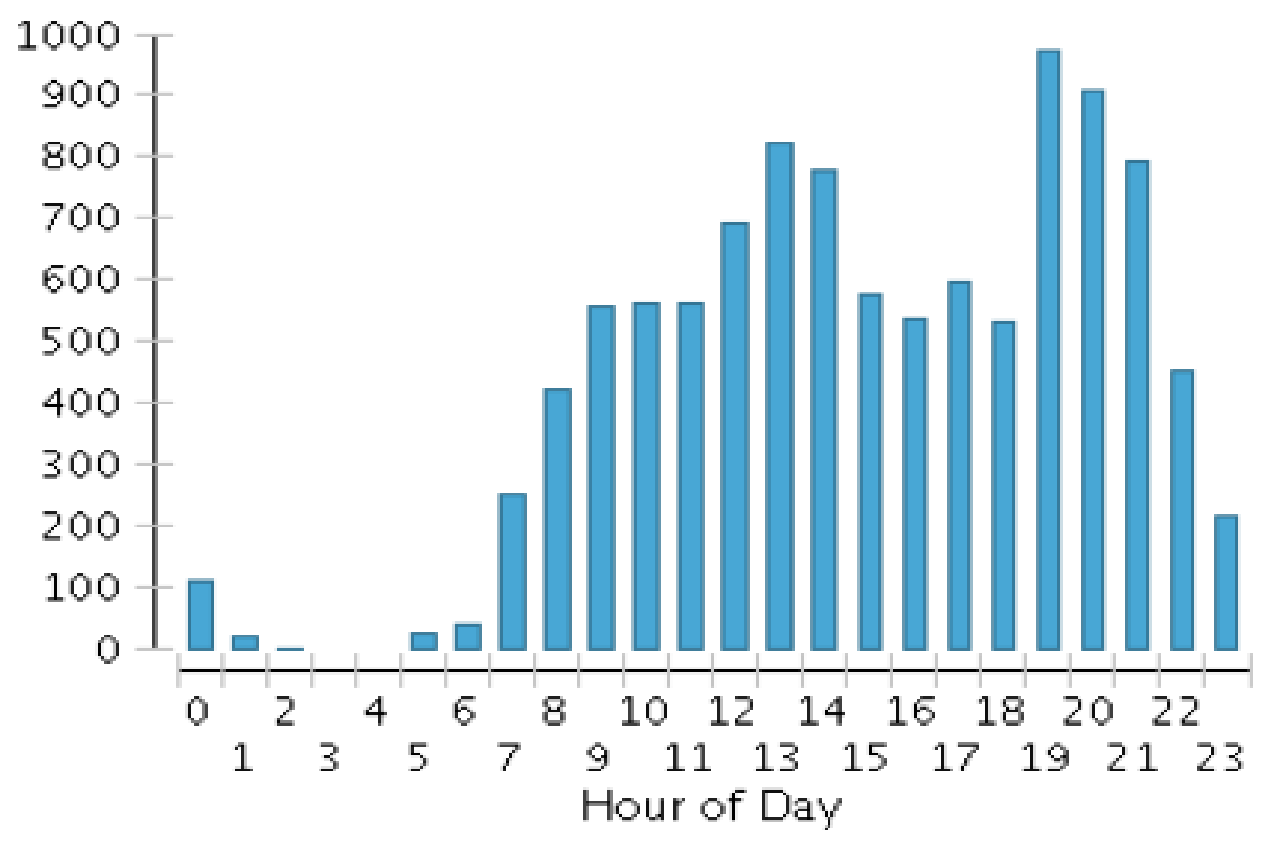

Figure 1. Learning Time of Day. 
in this study (Figure 2). Students had the most visiting numbers at the beginning of the month.
Visiting number of each learning module was also collected and analyzed (Figure 3 ). The course content module had the highest

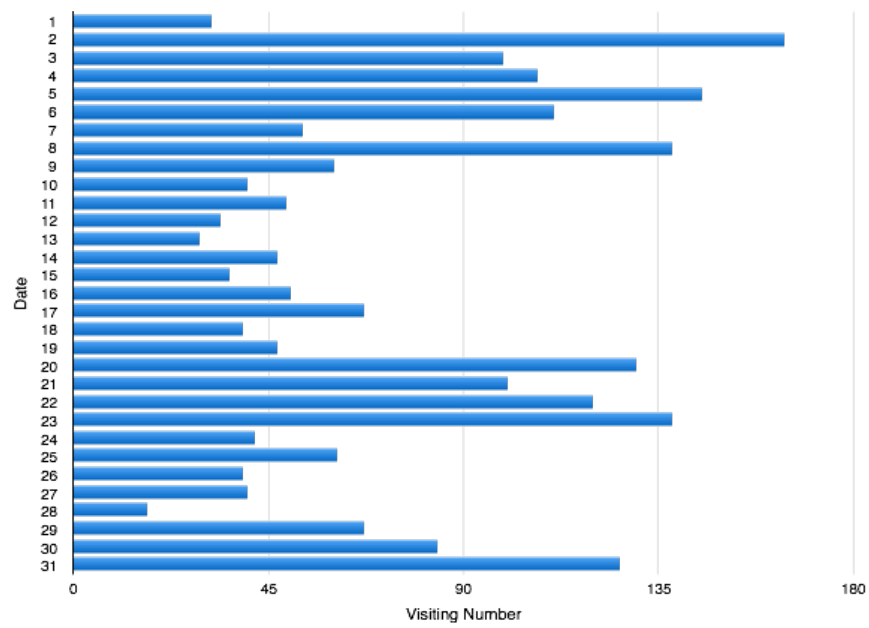

Figure 2. Monthly Visiting Number of Each Student.

visiting numbers, which was not surprising. The average visiting number of course content module was 200 times. Almost 40\% of students never used the Discussion Board, which was designed to provide peer interaction and learning support. Even for students who used Discussion module, only a few visiting numbers occurred. For instance, the second student only visited the Discussion module 5 times.

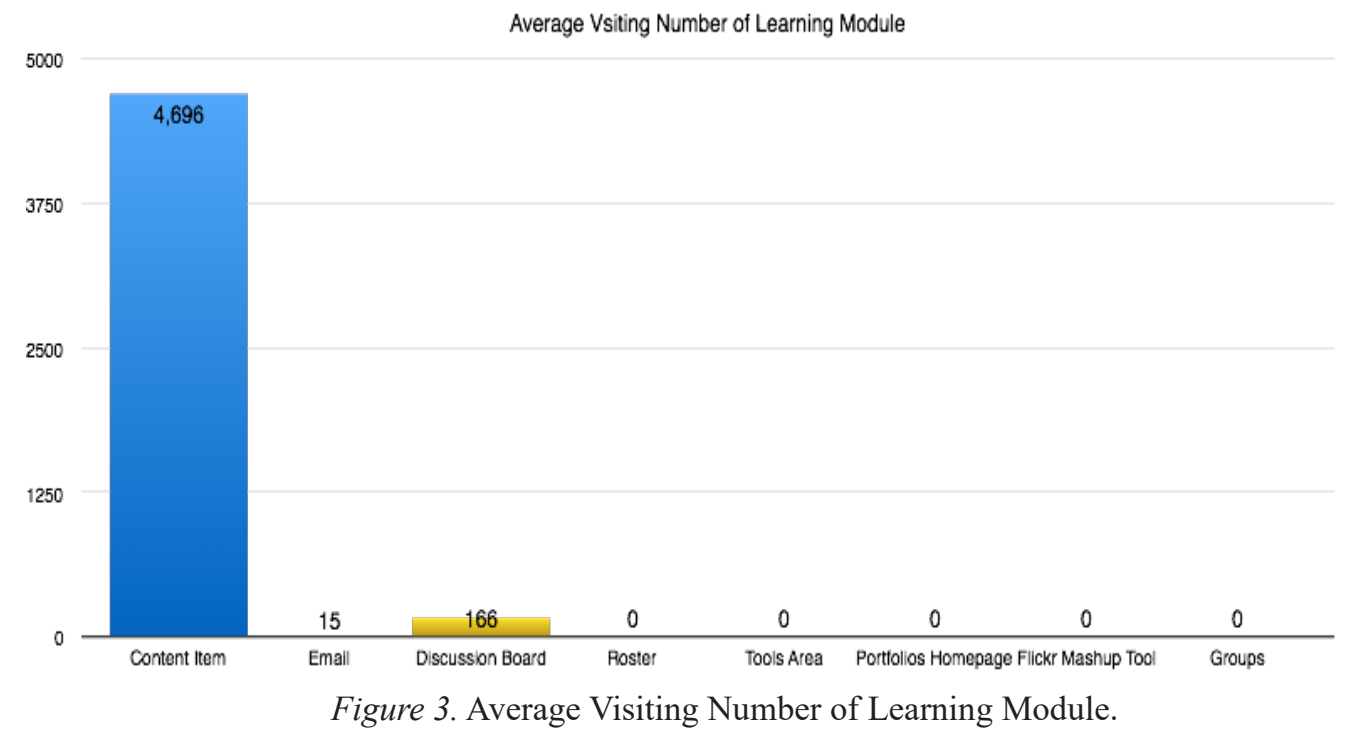

Volume 10, No. 2, December, 2017 


\subsection{Learning devices}

The devices students used to access the learning management system were tracked and analyzed through the embedded Google
Analytics in the learning management system. Desktop was the most widely used device for this online course learning (Table 4). Seventyeight percent of students used desktop for online learning, 19.4\% used mobile devices and the remaining $2 \%$ used tablets.

Table 4. Summary of learning devices

\begin{tabular}{|c|c|}
\hline Device Category & Usage (\%) \\
\hline Desktop & 78.6 \\
\hline Mobile & 19.4 \\
\hline Tablet & $2 \%$ \\
\hline
\end{tabular}

Since mobile devices was the second most popular learning device, specific device information was collected to further study mobile learning support (Table 5). There were more than $75 \%$ of students who used an Apple iPhone as a mobile learning device. Android devices, such as Motorola phones, were also used in this course, which accounted for an additional $17 \%$. The remaining $8 \%$ of students' chose the Apple iPad.

Table 5. Summary of mobile learning device

\begin{tabular}{|c|c|}
\hline Mobile Device Info & Usage (\%) \\
\hline Apple iPhone & 75 \\
\hline Motorola XT 1030 & 17 \\
\hline Apple iPad & 8 \\
\hline
\end{tabular}

Operating system information was another type of data collected in this study (Table 6). The Windows operating system had similar users as the Macintosh operating system, which were $33 \%$ and $30 \%$ respectively. The iOS system was another popular operating system that was used by $18 \%$ of users

Table 6. Summary of operating system

\begin{tabular}{|l|c|}
\hline Operating System & Usage (\%) \\
\hline Windows & 33 \\
\hline Macintosh (installed on MacBook and iMac) & 30 \\
\hline iOS (installed on iPhone and iPad) & 18 \\
\hline Android & 9 \\
\hline Linux & 8 \\
\hline
\end{tabular}


The last type of device data was browser information (Table 7). More than half of the students $(55 \%)$ used Google Chrome in this class. Safari, which took up to $20 \%$ of usage, was the second most popular browser for students. Internet Explorer was the least used browser in this study a $7 \%$.

Table 7. Summary of browser

\begin{tabular}{|c|c|}
\hline Browser & Usage (\%) \\
\hline Chrome & 55 \\
\hline Safari & 20 \\
\hline Firefox & 18 \\
\hline Internet Explorer & 7 \\
\hline
\end{tabular}

\section{Discussion}

This study utilized learning analytics techniques to collect online learning data from the learning management system, information management system, teaching materials, students' assignments, and students' performances to improve learning support design for an undergraduate online course. Findings are discussed in the following sections.

\subsection{Instructional support}

Analyzing average learning hours for each grading level was found to be an effective method to examine the quality of course difficulty level design. Findings of average learning hours for each grading level were surprising and as were new findings that have not been addressed by previous instructional design assessment studies. Results showed that the difficulty level design for each grade level in this class was not appropriate to reflect students' real efforts in this course. Students have to spend four times of learning hours to earn a grade A as compared to the time spent to earn a grade B. Grade C students have to spend 24 times of learning hours of grade D students, however, the average learning hours for grade B is only 1.8 times of grade C learning hours. Students may get less motivated to get a better grade. Grade D students may not put more effort in this course when they know they need 24 more times of learning hours to get a $\mathrm{C}$. The same may hold for Grade B students in that they may stay at a $B$ grade when they need 4 more times of learning hours to get an A. As a result, it is observed that the instructor needs to adjust course difficulty level to better reflect students' efforts in this class.

Visiting number of learning module was found to be a good indicator of the quality of course content design. This finding is consistent with the findings of Greenhow et al.'s (2006) study that learners' data is very useful for instructors to improve course content design. In this study, low visiting number of learning modules, such as email and discussion board, indicates that learning module design of this course is not as effective as it is supposed to be. Students visited the discussion module only for the discussion assignments purpose. Few students re-visited the discussion board module after they 
completed the assignments. The discussion board module has not been used as a learning support module. It is recommended that the instructor modify this discussion module to ensure students use discussion module more effectively.

\subsection{Peer support}

Weekly learning hours, daily learning time, and student monthly visiting number were found to be good signals to determine when to provide timely peer support for online learners. This finding is consistent with the findings of Fidalgo-Blance et al.'s (2015) study that learning analytics is effective in providing peer support, such as group activities. In this study, online meetings are an important way for online learners to get peer support by participating in these meetings. Learning analytics results showed that online meetings scheduled for this course were not appropriate for learning. According to the course syllabus, three online meetings in this class were scheduled on Friday nights. Friday may not be a good time for students to participate in course meetings and/or work with peers because an average low learning hours were reported at 55.15. The design of having online meetings on Friday night is not as effective as it intends to be. By contrast, weekly learning hours showed that most students in this class liked to learn on Sundays at the beginning of the month with reported average learning hours of 105.45 . The time between $7 \mathrm{pm}$ and $9 \mathrm{pm}$ is the most preferred learning time and having meetings on Sundays between $7 \mathrm{pm}$ and $9 \mathrm{pm}$ can engage most of the students in class. Students are more likely to get peer support during this time than other time. Lastly, low learning hours on Thursdays at 46.93 and Saturdays at 57.40 showed students' low motivation for learning on Thursday and Saturday. Analysis of daily learning time confirmed the meeting time design and this finding improved Hondo's (2011) study by providing concise timing for instructors to provide peer support, which was not addressed. Based on the learning analytics results, instructors will find it easier to determine optimal timing of providing support compared to survey results. The analysis of students' assignments show that more peer support is needed for this course besides just online meetings. Other types of peer support, such as group discussion and peer evaluation, are recommended to include in this course's learning support design.

\subsection{Technical support}

Findings of technical support based on learning analytics are new findings that have not been addressed by prior learning analytics studies. Ensuring students' access to learning materials from all devices is very important for online learners (Lai \& Hwang, 2015). Learning device usage analysis showed the trend of students using mobile devices to access learning materials. However, in this study, little support was found to support mobile access. Tutorial support is the only technical support provided for students in this course and most tutorials are Windowbased tutorials. In this class, it is notable that $20 \%$ of students use mobile devices to access the learning management system and most of those mobile devices are iPhones. Windows-based tutorials are not enough for students who use mobile devices in this class. A recommendation for instructors is to provide extra tutorials for mobile devices, primarily iPhones. An additional suggestion is to use mobile friendly tools to develop online tutorials and other technical support materials so that students, no matter which devices they are using, are able to get the necessary technical support. 


\section{Limitation}

Limitation of this study is that learning activities outside of learning management system were not tracked in this study due to technical challenges. It is very likely that some learners will print out the learning materials first and read those learning materials later. It is difficult for learning management system to track such learning activities. Lacking learning data outside of learning management system may reduce the generality of findings from online learning environment to other learning environments such as face-to-face classroom setting. In addition, lacking learning data outside of learning management system may increase the difficulty of examining learning patterns and strategies and predicting learning behaviors. Further research is suggested to track and analyze learning data occurred outside of learning management system.

\section{Conclusions}

Ensuring quality of learning support is essential to course quality. This study explored how instructors can utilize learning analytics to improve learning support in an online learning environment, including instructional support, peer support, and technical support. Results indicated that learning analytics techniques could help instructors identify potential issues of learning support design, which were impossible to be addressed by traditional instructional design assessment methods. Additionally, this study demonstrated that instructors can utilize learning analytics as a tool to examine and improve online learning design. This study also provided an alternative option for an instructional designer to examine the quality of course design. Further research is suggested to explore how learning analytics can improve other aspects of instructional design, such as pedagogical design.

\section{References}

Chatti, M. A., Dyckhoff, A. L., Schroeder, U., \& Thus, H. (2012) A reference model for learning analytics. International Journal of Technology Enhanced Learning, 4(5), 318-331.

Creswell, J. W., \& Plano Clark, V. (2011). Designing and conducting mixed methods research (2nd ed.). Thousand Oaks, CA: Sage Publications.

Fidalgo-Blanco, A., Sein-Echaluce, M. L., García-Peñalvo, F. J., \& Conde, M. (2015). Using learning analytics to improve teamwork assessment. Computers in Human Behavior, 47(1), 149-156.

Grant, M. R. (2012). University of MissouriSt. Louis: Data-driven online course design and effective practices. Continuing Higher Education Review, 76(1), 183-192.

Greenhow, C., Dexter, S. \& Riedel, E. (2006). Methods for evaluating online, resource-based learning environments for teachers. Journal of Computing in Teacher Education, 23(1), 5-12.

Hernández-García, A., González-González, I, Jiménez-Zarco, A. I., \& ChaparroPeláez, J. (2015). Applying social learning analytics to message boards in online distance learning: A case study. Computer in Human Behavior, 47(1), 68-80.

Hondo, J. (2011). The Impact of Timing in Pedagogical Interventions. Saarbrücken, Germany: LAP Lambert Acad. Publ..

Ifenthaler, D. (2014). Development and validation of a learning analytics framework: Two case studies using support vector machines. Technology, Knowledge, and Learning, 19(1), 221240.

Jo, I., Kim, D., \& Yoon, M. (2014). Analyzing the log patterns of adult learners in LMS using learning analytics. Proceedings of 
the Fourth International Conference on Learning Analytics and Knowledge (pp. 183-187), Indianapolis, Indiana.

Kim, J., Jo, I., \& Park, Y. (2016) Effects of learning analytics dashboard: Analyzing the relations among dashboard utilization, satisfaction, and learning achievement. Asia Pacific Education Review, 17(1), 1324.

Lai, C. \& Hwang, G. (2015). An interactive peer-assessment criteria development approach to improving students' art design performance using handheld devices. Computers \& Education, 85(1), 149-159.

Larusson, J. A., \& White, B. (Eds.). (2014). Learning analytics: From research to practice. New York, NY: Springer-Verlag New York.

Lee, S. J., Srinivasan, S., Trail, T., Lewis, D., \& Lopez, S. (2011). Examining the relationship among student perception of support, course satisfaction, and learning outcomes in online learning. Internet and Higher Education, 14(3), 158-163.

Lockyer, L. \& Dawson, S. (2011). Learning design and learning analytics. Proceedings of the 1st International Conference on Learning Analytics and Knowledge. Banff, Canada: 153-156.

Lockyer, L., Heathcote, E., \& Dawson, S. (2013). Informing pedagogical action: Aligning learning analytics with learning design. American Behavioral Scientist: 57(10), 1439-1459.

Lonn, S., Aguilar, S. J., \& Teasley, S. D. (2015). Investigating student motivation in the context of a learning analytics intervention during a summer bridge program. Computers in Human Behavior, 47(1), 90-97.

Mattingly, K. D., Rice, M. C., \& Berge, Z. L. (2012). Learning analytics as a tool for closing the assessment loop in higher education. Knowledge Management \& E-Learning: An International Journal,
4(3), 236-247.

McLoughlin, C. (2002). Learner support in distance and networked learning environment: Ten dimensions for successful design. Distance Education, 23(2), 149-162.

Muilenburg, L. Y. \& Berge, Z. L. (2005). Student barriers to online learning: A factor analytic study. Distance Education, 26(1), 29-48.

Mullen, G. E., \& Tallent-Runnels, M. K. (2006). Student outcomes and perceptions of instructors' demands and support in online and traditional classrooms. The Internet and Higher Education, 9(4), 257266.

Papamitsiou, Z., \& Economides, A. (2014). Learning analytics and educational data mining in practice: A systematic literature review of empirical evidence. Educational Technology \& Society, 17(4), 49-64.

Saldana, J. M. (2013). The coding manual for qualitative researchers ( 2 nd ed.). Thousand Oaks, CA: Sage Publications.

Zhong, L. (2016). A systematic overview of learning analytics in higher education. Journal of Educational Technology Development and Exchange, 8(2), 39-54.

\section{Contact the Author}

\section{Lin Zhong}

Southern Illinois University Carbondale, USA

Email:lin.zhong@siu.edu 